\title{
Peripheral and central mechanisms of visceral sensitization in man
}

\author{
P. ANAND,${ }^{\star}$ Q. AZIZ,$\dagger$ R. WILLERT $\dagger \&$ L. VAN OUDENHOVE $\dagger+$
}

*Peripheral Neuropathy Unit, Department of Clinical Neuroscience, Imperial College London, London, UK $\dagger$ Department of Gastrointestinal Science, Hope Hospital, University of Manchester, Manchester, UK

$¥$ Department of Neuroscience, Division of Psychiatry and Department of Pathophysiology, University Hospital Gasthuisberg, University of Leuven, Leuven, Belgium

\begin{abstract}
Visceral hypersensitivity (perception of gastrointestinal sensory events at a lower-than-normal threshold) is considered to be an important pathophysiological mechanism in the development of functional gastrointestinal disorders (FGIDs), such as irritable bowel syndrome, non-cardiac chest pain and functional dyspepsia. These disorders are associated with significant health care and socioeconomic costs due to factors such as repeated visits to consultants, hospitalizations and work absenteeism. Despite the presence of extensive evidence linking visceral hypersensitivity and FGIDs, the mechanism(s) underlying visceral hypersensitivity has not been fully elucidated. Suggested hypotheses include sensitization of afferent neurones, both at the level of the enteric and the (afferent) autonomic nervous system (peripheral sensitization), sensitization of spinal cord dorsal horn neurones (central sensitization) and psychosocial factors/psychiatric comorbidity influencing the processing of afferent signals at the level of the brain. Importantly, these hypotheses may be complementary rather than mutually exclusive. However, the degree to which each of these mechanisms contributes to the overall perception of visceral pain, and therefore the generation of symptoms, still remains unclear. This article discusses the mechanisms that may underlie visceral hypersensitivity, with reference to FGIDs. Understanding these mechanisms is essential in order
\end{abstract}

Address for correspondence

Lukas Van Oudenhove MD, Department of Gastrointestinal Science, University of Manchester, Clinical Sciences Building, Hope Hospital, Stott Lane, Salford M6 8HD, Greater Manchester, UK.

Tel: +44 16 12061442; fax: +441612064364

e-mail: lukas.vanoudenhove@med.kuleuven.be

Received: 13 October 2006

Accepted for publication: 24 October 2006 to improve the diagnosis and treatment of patients with these disorders.

Keywords brain-gut axis, central and peripheral sensitization, functional gastrointestinal disorders, psychosocial factors, visceral hypersensitivity, visceral pain.

\section{INTRODUCTION}

Chronic unexplained symptoms are common to all medical specialties. They cause considerable morbidity and have enormous health care resource implications. Extensive investigations are conducted without benefit and inappropriate treatment leads to poor patient satisfaction. Understanding the pathophysiological mechanisms underlying these conditions has, therefore, become one of the major challenges for medicine in the 21 st century.

Unexplained abdominal symptoms account for $40 \%$ of gastroenterological practice in the United Kingdom. These problems are usually classified as functional gastrointestinal disorders (FGIDs), a term that includes irritable bowel syndrome (IBS), non-cardiac chest pain (NCCP) and functional dyspepsia (FD). Despite extensive research in this area, the pathophysiology of FGID remains uncertain. The quest to identify an organic cause for symptoms leads to extensive investigation and frequent hospital attendance, which exerts a considerable financial strain on health service resources. ${ }^{1}$ A socioeconomic study estimated that the combined cost of health care utilization and job absenteeism related to FGID is $\$ 41$ billion per annum in the eight leading Western economies. ${ }^{2}$

Heightened perception of gastrointestinal (GI) sensation (visceral hypersensitivity) is commonly observed in patients with unexplained abdominal pain. ${ }^{3}$ Studies using mechanical and electrical stimulation have 
reproducibly demonstrated that patients with FGID have lower GI pain thresholds in comparison to healthy subjects. ${ }^{4-6}$ Furthermore, generalized somatic pain hypersensitivity is not apparent in FGID as studies have demonstrated that cutaneous pain thresholds in IBS and NCCP patients are similar or even higher than in controls, ${ }^{4,7}$ although lower cutaneous pain thresholds were also found in some studies. ${ }^{8}$

Despite extensive research to understand mechanisms of visceral hypersensitivity in FGID, the dichotomy between a purely psychological explanation and a purely organic explanation remains unaddressed. Evidence for a purely psychological explanation comes from studies in FGID patients who have shown a high incidence of psychological/psychiatric problems, ${ }^{9}$ not only in tertiary care samples but possibly also in the community. ${ }^{10}$ Furthermore, experimental evidence from animal and human studies suggests that acute stress and anxiety alter GI function, ${ }^{11-15}$ and animal studies show that stress such as maternal separation in childhood can lead to visceral hypersensitivity in adult life. ${ }^{16}$ It is notable, however, that while psychological therapy improves well-being, it does not improve symptoms, ${ }^{17}$ suggesting that psychological problems may be more relevant to health-care-seeking behaviour rather than underlying the disease pathogenesis. ${ }^{18}$ Evidence for a purely organic cause is provided by animal and human studies which clearly demonstrate that inflammation of the GI tract leads to visceral hypersensitivity due to increased sensitivity of afferent pathways. ${ }^{19,20}$ Furthermore, a third of FGID patients give a prior history of gut inflammation or injury such as gastroenteritis ${ }^{21}$ or abdominal surgery. ${ }^{22}$ However, patients who go on to develop FGID after gastroenteritis have a higher incidence of antecedent psychological problems, ${ }^{23,24}$ suggesting an interaction between psychological and organic aetiologies.

Functional dyspepsia, for example, has been consistently reported to be associated with abnormalities in gastric sensorimotor function (reviewed in Ref. $^{25}$ ), including hypersensitivity to gastric distension, ${ }^{26}$ abnormal gastric compliance, ${ }^{25}$ impaired gastric accommodation to a meal ${ }^{27}$ and delayed gastric emptying. ${ }^{28}$ Moreover, psychosocial stressors (including history of sexual or psychological abuse), personality traits (e.g. neuroticism) and psychiatric disorders (e.g. mood and anxiety disorders) as well as somatization are frequently present in FGID patients, in tertiary care samples and in the community. ${ }^{10,29-32}$ However, it is still unclear how psychosocial factors may interact with GI sensorimotor function in general and with visceral sensitivity in particular, in both health and FGID.
To explain the association between FGID, GI sensorimotor function and psychosocial factors, several potentially overlapping hypotheses have been put forward. ${ }^{31,33-37}$ Firstly, a direct (neuro)biological and possibly reciprocal interaction may exist between psychosocial factors or psychiatric disorders and GI sensorimotor function, the biological substrate for this being the reciprocal connection between the brain and the gut [brain-gut axis (BGA)]. ${ }^{33,38}$ This hypothesis implicates that psychosocial factors play a key role in FGID pathophysiology. Secondly, psychosocial factors or psychiatric disorders may influence gastric sensitivity through 'psychological' processes (arousal, anticipation/expectation, attention to/interpretation of bodily feelings and visceral-specific anxiety) that may influence symptom perception and/or symptom reporting. It should be noted, however, that it is well known from psychological, cognitive and pain neuroscience literature that these psychological processes have neurobiological correlates in the brain. ${ }^{37,39-45}$ Thirdly, psychosocial factors may not have a direct influence on GI sensorimotor function, but may only influence health care seeking or quality of life in FGID. ${ }^{31,35,46}$ Finally, FGIDs or visceral hypersensitivity and psychiatric disorders may be manifestations of a common (genetic) predisposition ${ }^{36}$ (e.g. serotonin transporter polymorphisms ${ }^{47}$ ); this may lead to theories stating that they are nothing more than epiphenomena.

Based on current scientific evidence, a number of hypotheses have been proposed to explain the mechanism of visceral hypersensitivity. These include (i) sensitization of GI afferent nerves [peripheral sensitization (PS)], (ii) sensitization of spinal cord dorsal horn neurones [central sensitization (CS)], (iii) altered descending excitatory or inhibitory influences to the spinal cord nociceptive neurones (which may be influenced by psychological processes) and (iv) misinterpretation of non-noxious sensation as noxious due to cognitive and emotional biasing (hypervigilance), the result of psychiatric/psychological disorders.

The following sections summarize the role of PS/CS, altered descending influences on the spinal cord, psychological factors including hypervigilance and the putative interactions between these mechanisms.

\section{PERIPHERAL SENSITIZATION}

Tissue damage due to inflammation leads to sensitization of primary afferent nerves (PS) due to the release of inflammatory mediators, such as $\mathrm{K}^{+}, \mathrm{H}^{+}$, adenosine triphosphate (ATP), bradykinin, prostaglandins, serotonin and histamine. ${ }^{48,49}$ These inflammatory mediators reduce the transduction threshold of primary 
afferents and recruit previously silent nociceptors. ${ }^{49}$ Inflammation also induces increased expression of sodium channels Nav 1.8 and 1.9 (SNS1 and 2), the vanilloid receptor transient receptor potential vanilloid type 1 (TRPV1 or VR1), the purine receptor $\mathrm{P}_{2} \mathrm{X}_{3}$ and acid-sensing ion channels (ASICs). ${ }^{50-53}$ Furthermore, cytokines secreted by macrophages and mast cells contribute indirectly to nerve sensitization by upregulating the expression of nerve growth factor $(\mathrm{NGF})^{54}$ and cause the release of cyclo-oxygenase metabolites ${ }^{5,56}$ and sympathomimetic amines. The consequence of these changes is an increase in pain sensitivity at the site of inflammation. ${ }^{49}$

Immunocytochemical techniques have recently been used to demonstrate an upregulation of peptides, cytokines, TRPV1 receptor and neurotrophic factors in skin, urinary bladder and rectal biopsies of patients with chronic hypersensitivity states without evidence of overt inflammation. ${ }^{57}$ Upregulation of TRPV1 has also recently been demonstrated in patients with idiopathic vulvodynia, ${ }^{58}$ which further suggests that the TRPV1 receptor may be an important marker of afferent nerve sensitization. An upregulation of TRPV1, P2X $\mathrm{X}_{3}$ receptors and ASICs has also been identified in the inflamed human GI tract. ${ }^{50,51,53}$ Recent studies have demonstrated that patients with oesophagitis have an upregulation of both TRPV1 ${ }^{59}$ and cytokine interleukin- $8 .^{60}$ These studies show that it is now possible to explore what receptors play an important role in mediating visceral hypersensitivity.

\section{CENTRAL SENSITIZATION}

Enhanced nociceptor input activates intracellular signalling cascades within spinal dorsal horn neurones. This leads to amplified responses to both noxious and innocuous inputs, due to facilitated excitatory synaptic responses and depressed inhibition. ${ }^{61-63}$ Facilitation is triggered by the presynaptic release of neurotransmitters and neuromodulators, such as glutamate, substance $\mathrm{P}(\mathrm{SP})$, brain-derived neurotrophic factor (BDNF) and prostaglandins. These neurotransmitters and neuromodulators activate ligand-gated ion channels including $N$-methyl-D-aspartate (NMDA) and $\alpha$-amino5-hydroxy-3-methyl-4-isoxazole propionic acid (AMPA) receptors, G-protein-coupled metabotropic receptors, neurokinin receptors and tyrosine kinase receptors, which then increase intracellular calcium via release from intracellular stores and calcium inflow. Subsequently, alterations in ion channel and receptor activity via calcium-dependent activation of protein kinase A (PKA), protein kinase $\mathrm{C}(\mathrm{PKC})$ and tyrosine kinases lead to phosphorylation of the NMDA receptors. ${ }^{49}$ This dramatically changes NMDA receptor kinetics and reduces its voltage-dependent magnesium block, thus augmenting its subsequent responsiveness to glutamate and increasing synaptic strength, enabling previously subthreshold inputs to activate the cell. ${ }^{64,65}$ This increase in gain alters receptive field properties and pain sensitivity, causing tissue hypersensitivity far beyond the site of injury that initiated CS.

In addition to producing CS, which occurs within seconds of appropriate activation of spinal dorsal horn neurones, nociceptive input also generates an activitydependent change in transcription in dorsal root ganglion and dorsal horn neurones. ${ }^{66}$ These transcriptional changes occur in response to a complex mechanism involving the activation of transcription factors that lead to both an increase and a modification of constitutively expressed genes and also induction of novel genes. For instance, non-nociceptive afferents begin to express SP and BDNF after inflammation ${ }^{67}$ and this phenotypic shift results in allodynia, i.e. non-nociceptive tactile stimuli now induce pain. These changes take hours to manifest but, when established, lead to long-lasting changes in normal stimulus response characteristics.

A striking feature of the increase in synaptic efficacy characteristic of CS is that it includes not only those nociceptor central terminal synapses activated by the conditioning stimulus but also synapses made by lowthreshold mechanosensitive $\mathrm{A} \beta$ fibres on dorsal horn neurones. ${ }^{68,69}$ Low-threshold sensory fibres, activated by innocuous stimuli such as light touch, can now activate normally high-threshold nociceptive neurones at the dorsal horn, contributing to a reduction in pain threshold such that non-painful stimuli are now perceived as pain (allodynia), which is a direct consequence of an increased excitability of central nervous system (CNS) neurones. Although this pain is referred to the periphery, it arises from within the CNS. This central facilitation manifests within seconds of an appropriate nociceptive conditioning stimulus and can outlast the stimulus for several hours. ${ }^{70}$ If the stimulus is maintained, even at low levels, the CS persists. After peripheral nerve injury, for example, ongoing ectopic activity arising from sensory fibres in the injured nerve can elicit prolonged CS. ${ }^{71}$

Such activity-dependent CS is extremely robust and has been reported in rodent, cat and primate dorsal horn neurones, including spinothalamic neurones. ${ }^{72-76}$

The behavioural consequences of CS can be readily detected in human psychophysical experiments. Intradermal injection of capsaicin, the pungent ingredient in chilli peppers, which activates the TRPV1 receptor, produces an intense but transient pain owing to activation of TRPV1-expressing nociceptors. This is 
followed by heightened sensitivity to pinprick outside the region of the capsaicin injection (secondary mechanical hyperalgesia) and to low-threshold mechanosensory (brush) inputs (secondary mechanical allodynia), due to the induction of CS. ${ }^{77-79}$ Clinically, CS has been demonstrated to contribute to pain hypersensitivity in the skin, ${ }^{80}$ muscle ${ }^{81}$ joints ${ }^{82}$ and viscera. ${ }^{4}$

Central sensitization also plays a major role in the generation of acute postoperative and post-traumatic pain, ${ }^{83,84}$ migraine and neuropathic pain. ${ }^{85-87}$ Interestingly, some clinical conditions, such as tension-type headache and fibromyalgia, appear not to be a reaction to a peripheral pathology but instead an expression of the presence of $\mathrm{CS}_{1}^{88,89}$ but why CS manifests apparently spontaneously in these patients remains to be established.

\section{ASCENDING AND DESCENDING VISCERAL PAIN PATHWAYS: THE BRAIN- GUT AXIS}

Knowledge of the bidirectional communication system between the gut [enteric nervous system (ENS)] and the brain (CNS), classically termed the BGA is critical for understanding a putative influence of psychosocial factors on GI sensitivity and motor functions. The ENS and the CNS communicate through neural (autonomic nervous system), neuroendocrine (hypothalamo-pituitary-adrenal axis) and neuroimmune pathways, and these systems may highly interact, for example, through cytokine receptors on the vagus nerve. ${ }^{90}$ An extensive review falls beyond the scope of this article (see $\operatorname{Refs}^{33,91}$ ), but we will provide a brief overview of the most important structures and their functions, with emphasis on the neural pathways involved in GI sensitivity.

\section{Ascending pathways}

Gastrointestinal sensory information is transmitted to the brain through vagal and spinal afferent nerves. Vagal afferents project to the nucleus of the solitary tract, which in turn projects to the thalamus (mostly via the parabrachial nucleus) and directly to regions regulating arousal and emotional, autonomic and behavioural responses including the hypothalamus, locus coeruleus (LC), amygdala and periaqueductal grey (PAG). From the thalamus, GI sensory signals are relayed to the cortical components of the 'visceral sensory neuromatrix' (see below). ${ }^{33,91}$

First-order spinal afferent nerves make synapse in the dorsal horn of the spinal cord and second-order neurones project to the brain through the spinoreticular, spinomesencephalic, spinohypothalamic and spinothalamic tracts. ${ }^{33,92}$ The first three of these tracts mainly activate fast, largely unconscious and/or automatic responses to visceral sensory input (arousal, orientation, autonomic responses, prototype emotional and behavioural responses), thereby playing a key role in maintaining the homeostasis of the organism. ${ }^{33,92}$

The spinothalamic tract projects to the ventral posterior lateral, medial dorsal and ventral medial posterior nuclei of the sensory thalamus, from which information is relayed to the somatosensory cortices (SI/SII) (lateral pain system), the anterior cingulate cortex (ACC) (medial pain system) and the insula, respectively. ${ }^{33,92}$ In these cortical regions, conscious and more complex processing takes place. The main function of SI/SII is to provide information about intensity and localization of the stimulus (sensorydiscriminative pain dimension), whereas the ACC mainly processes pain affect (affective-motivational pain dimension). The different subregions within the ACC are also important in generating autonomic, behavioural and descending antinociceptive responses to (visceral) pain, ${ }^{33,92}$ and in anticipation of or attention to aversive (visceral) stimuli. ${ }^{37}$ The insula is the 'interoceptive cortex' where all information about the internal state of the organism is processed, ${ }^{39}$ playing an important role in integrating visceral sensory and emotional information and in higher order control of autonomic visceromotor responses. Finally, the orbital prefrontal cortex is playing a key role in the integration of sensory information from different modalities (especially related to food and eating) and attributing affective, motivational, reward and hedonic valence to it. ${ }^{93}$ Furthermore, this region is also involved in the generation of and choice between autonomic and behavioural response patterns, ${ }^{93}$ and has been shown to be a putative biological substrate of cognitive influences (including placebo effect and expectation of relief) on emotions and the affective dimension of (visceral) pain. ${ }^{42}$

Thus, different dimensions of visceral sensation and pain are processed at the different levels of the ascending part of the BGA as described. However, descending pathways originate at virtually all BGA levels to modulate the ongoing transmission of visceral sensory information, mainly at the level of the dorsal horn of the spinal cord. ${ }^{91}$

\section{Central descending facilitatory pathways}

The excitability of viscerosomatic afferents within the ventral horn, which project to the anterolateral 
ascending pathways, can be enhanced by stimulation of the reticular formation of the nucleus raphe magnus. This is part of the excitatory spino-bulbo-spinal feedback loop, which is conveyed within the venterolateral funiculus to excite spinal cord neurones. ${ }^{94-96}$ The role of this excitatory pathway is thought to be to activate the descending antinociceptive system to the dorsal horn via the nucleus raphe magnus and to activate arousal and emotional responses via autonomic nuclei. ${ }^{97}$

\section{Central descending inhibitory pathways}

Viscerosomatic spinal neurones can not only be excited by visceral afferent activity but also be inhibited. The inhibitory neurones are thought to have a modulatory role in visceral pain. For example, visceral stimulation can induce excitation of innervating neurones and inhibit non-innervating spinal neurones so that the ascending information within the cord is enhanced from this organ, ${ }^{98}$ hence making it easier to interpret the source of afferent information for the brain. Other viscerosomatic neurones that innervate the viscera can be inhibited by either a visceral or somatic input for up to $1 \mathrm{~s}$, so that no afferent response to a further input during this period occurs. ${ }^{96}$ While their role is not fully understood, the activity of these viscerosomatic afferents may explain the intermittent rhythmic nature of abdominal colic. These neurones have also been implicated in explaining the phenomena called counterirritation, ${ }^{99}$ where the pain threshold in the viscera is increased following noxious somatic stimulation within its segmental spinal innervation.

Besides local spinal inhibitory pathways, it is well recognized that spinal nociceptive transmission is modulated by descending pathways from various supraspinal structures, including the nucleus raphe magnus, periventricular grey of the hypothalamus and the midbrain PAG. ${ }^{100,101}$ At cortical level, the ACC is the most important source of descending modulatory pathways, projecting to the amygdala and the PAG, which is probably the key pain modulatory region. On a lower brainstem level, the noradrenergic LC, the serotonergic raphe nuclei and the rostrolateral ventral medulla (RVM) receive input from the amygdala and the PAG, and project in turn to the dorsal horn of the spinal cord, where ongoing transmission of sensory information is modulated (gate mechanism). ${ }^{91,102}$ Throughout the whole descending modulatory system, from cortex (ACC) to PAG and spinal cord (dorsal horn), endogenous opioids are crucially involved, together with other neurotransmitters including serotonin and noradrenaline. ${ }^{102}$
Thus, similar to its somatic counterpart, visceral nociceptive transmission is also subject to descending inhibitory modulation. ${ }^{103-105}$ This is evident in the responses of dorsal horn neurones to noxious colorectal distension, which were inhibited by electrical or chemical stimulation applied within the PAG. ${ }^{105}$ More recently, the visceromotor response (contraction of abdominal and hind limb musculature) and the spinal dorsal horn neuronal responses to colorectal distension have been shown to be modulated in a biphasic manner by chemical stimulation in the brainstem RVM. ${ }^{106}$ The interaction between the descending facilitatory and inhibitory systems from the RVM appears to produce a net facilitatory effect following tissue injury, perhaps as an evolutionary defence mechanism to enable protection of the injury. The neuromodulators producing these effects are only now beginning to be understood, but it appears that activation of NMDA receptors and production of nitric oxide are important in the descending facilitatory pathway, ${ }^{107}$ while nonNMDA receptors mediate the inhibitory descending pathways. ${ }^{108,109}$

\section{MECHANISMS OF VISCERAL PAIN HYPERSENSITIVITY}

Although visceral pain hypersensitivity has been widely demonstrated in FGID, the pathophysiological mechanisms to account for such hypersensitivity are not well characterized. Alterations in the pain transduction pathways may occur throughout the BGA from the primary afferent, through the spinal cord to the brainstem and higher centres. Subsequent neural pathways from the brain to the gut via vagal and spinal efferents will modulate this sensory input, resulting in either a facilitatory or inhibitory response to the visceral stimulus.

\section{Peripheral mechanisms}

The development of PS of visceral afferent fibres has been shown to cause long-term sensorimotor disturbances of the gut when the inflammation subsides ${ }^{110}$ and neonatal visceral inflammation has been shown to cause long-term colonic hyperalgesia in adult rats. ${ }^{19,111}$ These results suggest that either persistent sensitization of primary afferent neurones or synaptic plasticity within the CNS can occur long after the resolution of the insult. It is therefore conceivable that a disorder now labelled as functional had an antecedent peripheral initiating event. Evidence for this hypothesis is seen in patients with postinfectious IBS (PI-IBS) who give a preceding history of GI infection prior to the 
onset of their symptoms. Increased mast cells, $\mathrm{T}$ lymphocytes and expression of interleukin- $1 \beta$ have been observed in the large bowel in PI-IBS patients. ${ }^{20,112}$ Furthermore, recent data have shown close proximity of mast cells and nerves, with a correlation to abdominal pain severity in IBS patients. ${ }^{113}$ This suggests a neuroimmune interaction in IBS and is supported by demonstrations that SP can alter mast cell excitability and function via neurokinin-1 (NK-1) receptors on mast cells, ${ }^{114}$ with NK-1 receptor expression being influenced by interleukin-4 production from $\mathrm{T}$ lymphocytes. ${ }^{115}$ Therefore, changes in peripheral neuroimmune interactions may contribute to the pathophysiology and clinical expression of altered visceral pain hypersensitivity seen in FGID. ${ }^{116}$

Another potential mechanism for ongoing PS is nerve injury, as this is well known to cause long-lasting hyperalgesia in animal models of somatic neuropathic pain. Studies using a model of pelvic nerve damage in the rat have shown a reduced threshold to distension and increased spontaneous activity, ${ }^{117}$ suggesting that visceral nerve damage could significantly contribute to the afferent barrage arriving at the spinal cord in the absence of any peripheral inflammation. This could explain the anecdotal reports of patients with FGIDs pinpointing the onset of their symptoms to immediately after abdominal or pelvic surgery.

Peripheral inflammation could also potentially alter the phenotype of visceral afferent neurones such that an increased expression of ligand- or voltage-gated channels remains despite resolution of the inflammation. Candidate receptors include TPRV1, voltagegated calcium or sodium channels and stretch activated potassium channels. ${ }^{118}$

TRPV1 receptors The TRPV1 receptor, which is activated by heat and capsaicin, plays an important role in visceral hypersensitivity. First cloned in $1997,,^{119}$ the polymodal TRPV1 receptor belongs to the family of TRP receptors expressed particularly by small-sized afferent neurones and by mononuclear blood cells. ${ }^{120}$ TRPV1 is activated by capsaicin and its analogues, lipids, other molecules such as resiniferatoxin that contain a vanillyl moiety, and also by endocannabinoids including anandamide. ${ }^{119,121}$ Upon activation, a sensation of burning pain is evoked, along with release of the neuropeptides SP and calcitonin gene-related peptide. The receptor is also gated by noxious heat $\left(>43{ }^{\circ} \mathrm{C}\right)$, and its mechanism potentiated by protons. It has been suggested that inflammatory and ischaemic hyperalgesia may in part be mediated by the enhanced TRPV1 response resulting from a decreased tissue $\mathrm{pH}$ and production of excess hydrogen ions. ${ }^{119}$
In humans, there is increasing evidence that TRPV1 is involved in gut hypersensitivity and pain. Topical capsaicin has been shown to be an effective treatment for idiopathic pruritus ani, with the probable mechanism being functional desensitization of nociceptors by capsaicin. ${ }^{122}$ Hypersensitivity is likely to result from inflammatory products driving phenotypical changes in sensory neurones expressing TRPV1, mainly via increased NGF and/or glial-derived neurotrophic factor (GDNF).

Transient receptor potential vanilloid type 1 receptor expression changes have also been linked with other gut hypersensitivity disorders. Patients suffering from rectal hypersensitivity and faecal urgency have been found to have an increase in the TRPV1-expressing nerve fibres when compared with controls, and these levels correlated with a decrease in threshold to rectal heat and distension. ${ }^{57}$ This group of patients was also found to have increased GDNF and trk-A-expressing fibres (Fig. 1, from Ref. ${ }^{123}$ ).

TPRV1 has been implicated in the mechanism of pain produced in gastro-oesophageal reflux disease (GORD). In oesophagitis patients, the proportion of papillae positive for these nerve fibres was increased, suggesting that acid-induced inflammation may upregulate expression of acid-sensitive receptors such as TRPV1, hence contributing to the visceral hypersensitivity often seen in patients with GORD and chest pain. ${ }^{59}$ A recent study ${ }^{124}$ has revealed an increase in TRPV1-expressing nerve fibres in the oesophageal mucosa of patients with non-erosive reflux disease, further strengthening the hypothesis. This could provide an explanation for the distressing burning symptom which these patients complain of during reflux episodes and in response to alcohol, hot beverages and foods, via stimulation of TRPV1. Interestingly, a trial of FD patients treated with red pepper ${ }^{125}$ resulted in patients initially complaining of epigastric pain, followed by an improvement of symptoms after prolonged treatment for a few days. This is similar to the effect seen with capsaicin treatment of pruritus ani described above, suggesting initial stimulation of TRPV1-expressing neurones, followed by desensitization.

Capsaicin induces ileal pain when applied via ileal stomata. ${ }^{126}$ Schmidt et al. conducted a study which revealed that perfusion of capsaicin in the human jejunum in healthy individuals induced pain and warmth sensation indicative of activation of capsaicin-sensitive receptors, probably TRPV1. ${ }^{127}$ In patients with painful inflammatory bowel disease (IBD), the number of TRPV1-expressing neurones is significantly increased in colonic mucosa. ${ }^{51}$ 
Figure 1 TRPV1 and GDNF in rectal hypersensitivity. Capsaicin receptor (TRPV1) immunoreactive nerve fibres in control rectum (A) and rectal hypersensitivity (RH) (B) and GDNF-immunoreactive fibres in control column rectum $(\mathrm{C})$ and hypersensitive rectum (D). Scale bars: (a, b) $50 \mu \mathrm{m}$; (c, d) $100 \mu \mathrm{m}$. From Ref. ${ }^{123}$.
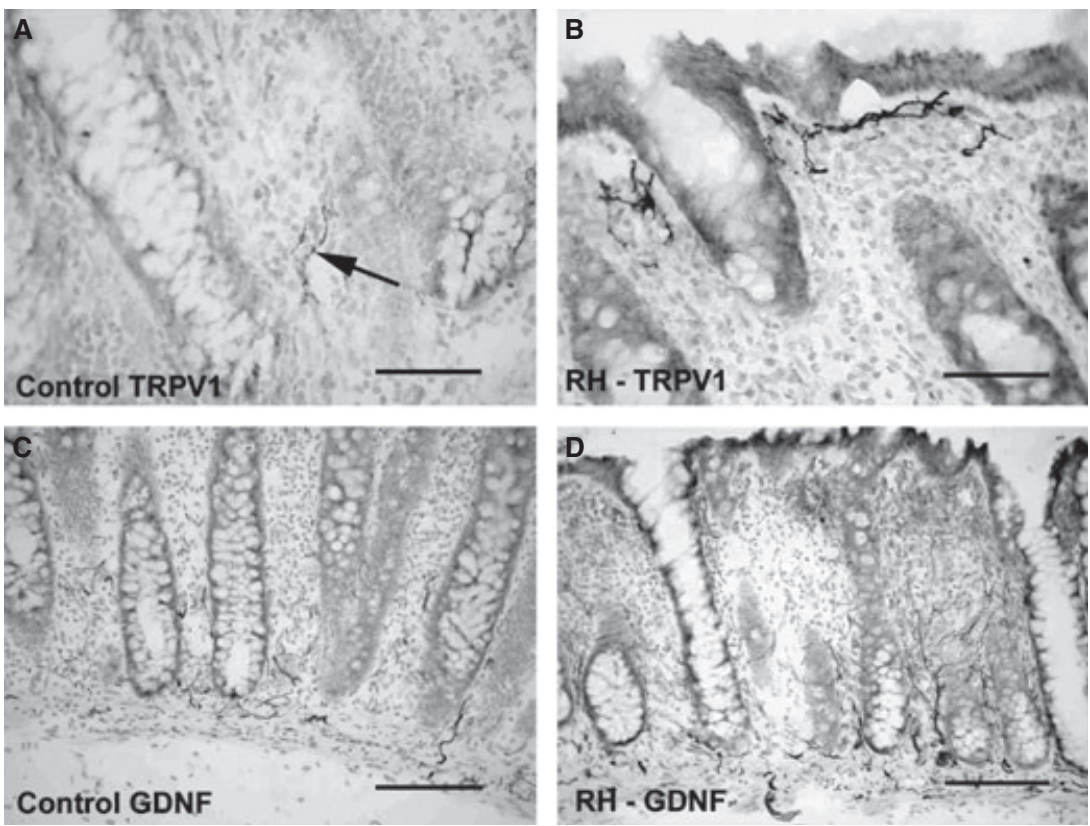

These studies in humans provide evidence of a role for TRPV1 in inflammation-induced pain and visceral hypersensitivity. The changes in expression are likely to be mediated by the effects of NGF, which is produced locally during inflammation. Nerve growth factor sensitizes TRPV1 receptors to protons, enhancing their effect, and also increases expression of TRPV1. Increased NGF and recently trk A expression have been reported in acute IBD. ${ }^{128} \mathrm{Ji}$ et al. have shown that the increase in TRPV1 levels which occur 12-24 h after inflammation is by an NGF-mediated p38 kinase pathway. ${ }^{129}$ TRPV1 activity is modulated by inflammatory mediators including bradykinin and prostaglandins, probably by cAMP-dependent PKA or PKC-mediated phosphorylation of the receptor. ${ }^{130}$

Possible mechanisms by which NGF can mediate hypersensitivity are summarized in Figs 2 and 3, reproduced with kind permission of The Lancet.

Acid-sensing ion channels Tissue damage, whether it be a result of trauma, infection, inflammation or ischaemia, results in local tissue acidosis and pain. Pain may be due to modulation of receptors, such as TRPV1, by acidic $\mathrm{pH}$ or by direct activation. A sodium selective channel, ASIC1, expressed by sensory neurones, is closed at a $\mathrm{pH}$ of 7.4, but is activated once the $\mathrm{pH}$ falls below 7.0. ${ }^{131}$ The related ASICs have been renamed as ASIC2a, ASIC2b and ASIC3.

These channels are likely to play a role in nociception and GI visceral hypersensitivity, but experimental evidence in humans is lacking at this stage. Yiangou et al. looked at ASIC expression in biopsies from actively inflamed Crohn's disease patients and found that ASICs 1, 2 and 3 were all expressed in the enteric neurones. Interestingly, only ASIC3 expression was significantly upregulated in the inflamed specimens when compared with controls, suggesting a role for ASIC3 in inflammation and pain/GI hypersensitivity. ${ }^{53}$ As acid-sensing channels, they would be a likely candidate for oesophageal pain provoked by acid, but further studies are warranted.

ATP-gated ion channels Ion channels that are gated by extracellular ATP have been characterized on sensory neurones including those in the intestine in animal studies. Two types of receptors exist: P2X receptors are ATP-gated and P2Y are G-protein-coupled receptors. ${ }^{132}$ In the GI tract, ATP release may occur from a variety of sources including cell damage, sympathetic and extrinsic sensory neurones, and hence ATP-gated ion channels are a likely candidate for mediating GI nociception following inflammation, infection or injury.

$\mathrm{P} \mathrm{X}_{3}$ receptors, a subgroup of the $\mathrm{P} 2 \mathrm{X}$ receptors, have been shown to be present in human enteric neurones. ${ }^{50}$ Yiangou et al. also found that in inflamed

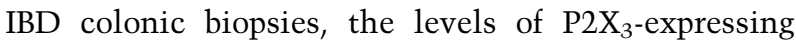
neurones were significantly increased. This human study implies that $\mathrm{P}_{2} \mathrm{X}_{3}$ have a role in inflammation, pain and dysmotility.

Voltage-gated sodium channels Voltage-gated sodium channels (VGSC), of which there are numerous in the central and peripheral nervous systems, ${ }^{133}$ are 

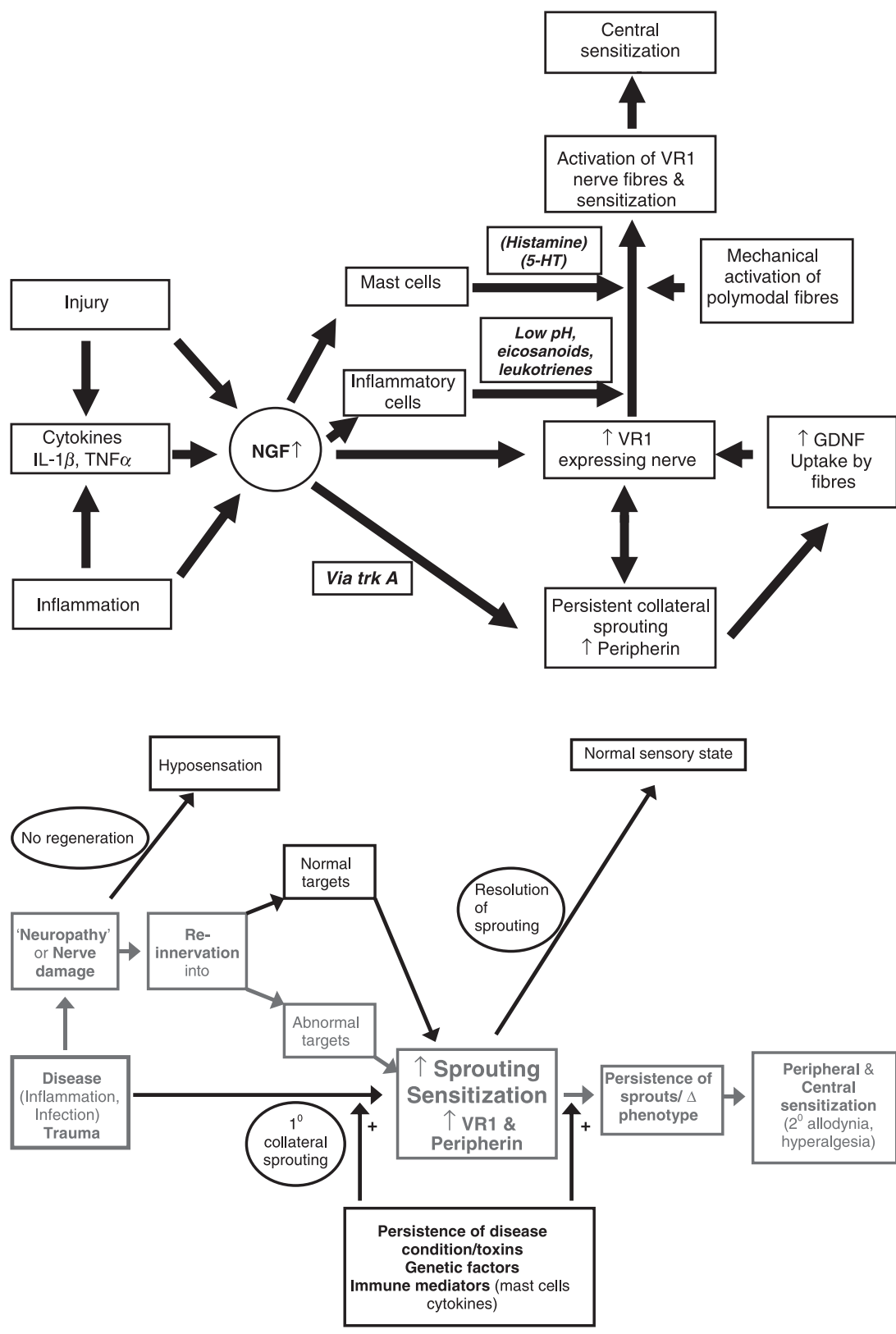

Figure 2 Proposed molecular mechanisms of hypersensitivity. Reproduced with kind permission of The Lancet. responsible for the rising phase of the action potential, ${ }^{66}$ by a voltage-dependent increase in sodium ion permeability. They are involved, along with potassium channels, in determining the excitability of sensory neurones. Classification into two types is possible: those sensitive to the potent puffer fish toxin tetrodotoxin (tetrodotoxin-sensitive) and those in the second group which are insensitive to tetrodotoxin [tetrodotoxin-resistant (TTXr), Nav 1.8 and 1.9]. ${ }^{134}$ Tetrodotoxin-sensitive channels are found in all sensory neurones, but TTXr channels are preferentially expressed by nociceptor sensory afferents. ${ }^{66}$ Tetrodotoxin-resistant sodium channels are likely to play an important role in nociceptive transmission and there is particular interest in the TTXr VSGC $\alpha$ subunit SNS Nav 1.8. With respect to TTXr sodium channels, in vitro work has shown that a number of inflammatory mediators such as prostaglandin E2 (PGE2), serotonin and adenosine increase the rates of activation and inactivation, decrease the activation threshold and increase the size of the current, ${ }^{134}$ i.e. cause sensitization. Animal studies reveal that TTXr sodium channels play an established role in sensitization of afferents and development of inflammatory hyperalgesia, and although experimental data in human studies is lacking, they are likely to be a key player. 
Mechanisms by which primary visceral afferent neurones contribute to visceral pain hypersensitivity may therefore include (i) peripheral inflammation, defined by ongoing cytokine expression in the absence of histological changes, (ii) visceral nerve damage and (iii) changes in the number or function of several ion channels, initiated and maintained by presently unknown means. All of these potential mechanisms could result in visceral pain hypersensitivity without further amplification of visceral afferent input to the CNS. However, it is more likely that the peripheral input adds to the CNS mechanisms, which also contribute significantly to visceral pain hypersensitivity.

\section{Central mechanisms}

Central sensitization Central sensitization is a key process in the development of persistent somatic pain hypersensitivity and there is an extensive body of literature that has highlighted the importance of SP, neurokinin B, PGE2 and the NMDA receptor in its development and maintenance at the spinal level. ${ }^{63}$ Evidence for a role of CS as a mechanism for the development and maintenance of visceral pain hypersensitivity comes from both animal and human studies. ${ }^{3,4,135-141}$

Animal studies have demonstrated that following somatic inflammation, a positive correlation exists between visceral pain thresholds and increased afferent discharge of dorsal horn neurones demonstrating viscerosomatic convergence. ${ }^{142-144}$ Spinal cFOS expression, used as a marker of dorsal horn activity, has also been shown to be increased following noxious colorectal distension ${ }^{145}$ and this is prevented by NMDA receptor antagonism. ${ }^{65,146}$

To address the question whether inflammation/ injury can induce CS in the human GI tract, a human model was developed, which demonstrated that infusion of hydrochloric acid into the healthy oesophagus reduced pain threshold not only in the acid-exposed region (PS) but also in the adjacent unexposed region (CS). This effect was prolonged, lasting up to $5 \mathrm{~h}$ after $30 \mathrm{~min}$ of acid exposure. The duration and magnitude of CS was related to the intensity of acid exposure. Repeat exposure after recovery significantly potentiates the effect of the first infusion, suggesting that repeated injury can induce a progressive increase in hypersensitivity.

A major limitation of most visceral hypersensitivity studies is that they rely on subjective methods of reporting sensation. ${ }^{184}$ To overcome this, a commonly used neurophysiological technique, cortical evoked potentials (CEP), has been developed as a more objec- tive correlate of oesophageal sensation. Cortical evoked potentials allows recording of cortical neuronal electrical fields generated in response to a peripheral nerve stimulus. Using this technique before and after acid infusion, a reduction in CEP latency was demonstrated, which suggests that facilitation of afferent pathway conduction accompanies the CS. ${ }^{140}$

To explore whether the mechanisms of CS (in an oesophageal model) are similar to those described in animal studies, pharmacological studies have been used to block receptors involved in CS.

A recent study showed that administration of an antagonist at the PGE2-receptor EP1 prior to acid infusion blocks the subsequent development of oesophageal hypersensitivity, suggesting that prostaglandins play an important role in mediating PS and CS. ${ }^{185}$

It was recently demonstrated that ketamine, an NMDA receptor antagonist, not only prevents the development of oesophageal hypersensitivity in response to acid infusion but that it also reverses already established hypersensitivity in an oesophageal model of CS in healthy volunteers. No consistent cognitive or analgesic effects of ketamine were observed at the doses used. ${ }^{141}$

That inflammation-evoked prostaglandin release through induction of cyclo-oxygenase-2 (COX-2) at the site of injury/inflammation is an important mechanism for the development of PS has long since been established. ${ }^{55,56}$ Prostaglandins also play a role in spinal mechanisms of hyperalgesia (CS). ${ }^{186-190,192}$ Using a selective oral COX-2 inhibitor (Valdecoxib; Bextra $^{\circledR}$, Pfizer Pharmaceuticals, no longer available on the UK and US market) in the oesophageal model of CS model in healthy subjects, ${ }^{191}$ it was demonstrated that the development and maintenance of acid-induced oesophageal hypersensitivity could not be attenuated by COX-2 inhibition.

Substance P and its receptor (NK-1) have been shown to have a role in pain and hyperalgesia, ${ }^{193-198}$ although results using NK-1 receptor antagonists (NK-1RA) in human somatic pain have been disappointing. ${ }^{199}$ Evidence for a role of SP in visceral nociception comes from several animal models, including NK-1 knockout mice, which have shown an effect of NK-1RA on reducing visceral hyperalgesia. ${ }^{200,201}$ In comparison to cutaneous afferents, a greater proportion of visceral afferent neurones contain SP $(80 \% \text { vs } 25 \%)^{202}$ and the highest concentration of NK-1 receptors in lamina I of the spinal cord correlates with termination of visceral afferent neurones. ${ }^{203}$ Therefore, an oral selective NK-1 receptor antagonist was used in the oesophageal model of CS in healthy subjects to assess the role of SP in human visceral hypersensitivity. ${ }^{204}$ This demonstrated 
that the hypersensitivity induced in the proximal oesophagus (secondary allodynia) by acid infusion in the distal oesophagus was not prevented by prior treatment with the NK-1 receptor antagonist. Furthermore, the NK-1RA did not alter baseline sensory or pain thresholds in either the oesophagus or foot (somatic control), demonstrating that NK-1 receptor antagonism does not influence normal human nociceptive processing in keeping with previous published studies. Whether combination therapy with NK1 plus NK2 or NK3 receptor antagonists is efficacious remains to be seen.

Psychological factors: hypervigilance, anxiety, stress and abuse history Hypervigilance is a normal physiological state of the nervous system in response to perceived threat and enhanced arousal can be associated with enhanced sensitivity to visceral sensations, as seen in healthy individuals with sensations of palpitations, urgency and 'butterflies' in the stomach when experiencing fear. Evidence (from neuroimaging studies, among others) now suggests that some patients with FGIDs are chronically hypervigilant to physiological visceral stimuli in that they selectively attend to normally subthreshold visceral inputs ${ }^{147}$ (see below for overview of neuroimaging evidence).

Patients with IBS often present during times of increased personal stress (although it is unclear whether stress initiates the disorder) ${ }^{11,12}$ and evidence for a role of stress in visceral pain hypersensitivity comes from animal models of IBS where inducing stress using maternal separation, ${ }^{16}$ water avoidance ${ }^{148}$ or foot shocks ${ }^{14}$ causes the animals to develop visceral pain hypersensitivity to colonic distension during further periods of stress. Corticotropin-releasing factor (CRF) is implicated in stress-induced visceral pain hypersensitivity as it is released by the hypothalamus during increased limbic activity, ${ }^{13}$ activates the hypothalamic-pituitary-adrenal axis and results in increased cortisol production which may then have a role in facilitating intestinal sensitivity and in increasing general arousal. ${ }^{149,150} \mathrm{~A}$ recent study has given clinical support for the role of CRF in visceral hypersensitivity as a CRF antagonist improved motility while reducing visceral perception and anxiety in IBS patients; ${ }^{151}$ further studies are awaited.

What causes some to become hypervigilant or hyperresponsive to stress while others do not remains unclear, but as with the animal models above, a previous history of childhood adversity or significant life stressor appears to modulate your responses to stress and is implicated in your future risk of developing an FGID. ${ }^{152}$

In a recent study in a large sample of tertiary care FD patients, factor analysis was performed on dyspepsia symptoms to define patient subgroups; associations of symptoms with gastric pathophysiological mechanisms and psychosocial factors/psychiatric comorbidity were determined. An association between gastric hypersensitivity, epigastric pain and burning and neuroticism, somatization, history of psychological abuse as a child or adult and quality of life was found. ${ }^{29}$

Another study has recently shown that normosensitive and hypersensitive FD patients do not differ in state anxiety at the day of their barostat investigation, nor in trait anxiety. However, within the hypersensitive subgroup, a significant negative correlation was found between state anxiety on one hand and gastric discomfort thresholds, pain thresholds and compliance on the other. These findings indicate that state anxiety may influence gastric sensorimotor function within the hypersensitive subgroup of patients, rather than distinguish between hyper- and normosensitive patients. ${ }^{153}$

Moreover, a history of sexual abuse, especially in childhood, has been shown to be associated with lower gastric discomfort threshold in FD, whereas psychological and physical abuse are associated with altered thresholds for first perception. ${ }^{154}$ In a sample of female IBS patients, however, a history of severe sexual or physical abuse was found to be associated with higher rectal pain thresholds. ${ }^{155}$ More research on this methodologically difficult issue is needed and the relationship between different forms of abuse history and pain thresholds is complex, ${ }^{156}$ but evidence that especially early abuse experiences can alter visceral and somatic pain sensitivity is growing.

It has also been shown that help-seeking IBS patients with comorbid psychiatric disorders are more likely to develop psychiatric disorders (especially anxiety disorders) before the onset of IBS. ${ }^{157}$ This may suggest that 'psychiatric symptoms, especially anxiety, play a role in the development of IBS, ${ }^{157}$

Finally, the evidence for a beneficial effect of psychotherapy and hypnosis in FGIDs is increasing $^{158-160}$ and these point towards central mechanisms playing an important role in visceral pain hypersensitivity as they are probably acting on the limbic system, to reduce the effects of stress on the BGA.

Endogenous pain modulation Descending CNS pathways from the RVM to the dorsal horn of the spinal cord are well described in somatic nociception ${ }^{161}$ where they have a tonic inhibitory effect. ${ }^{162}$ In contrast, spinal visceral nociceptive transmission has both descending facilitatory and inhibitory inputs that produce a net facilitatory effect. ${ }^{106}$ Alterations in this 
dynamic equilibrium between facilitatory and inhibitory inputs from the midbrain to the spinal dorsal horn neurones following central stress or peripheral inflammation could therefore result in enhanced visceral pain perception, due to enhanced descending facilitatory influences or reduced inhibitory inputs. ${ }^{163}$ To date, only indirect evidence from brain imaging studies exists in patients with FGIDs to assess the contributions of these pathways to symptom generation (see next paragraph). However, evolving neuroimaging techniques should soon enable more thorough investigation of brainstem processing of human visceral pain.

Evidence from brain imaging studies in visceral sensory and affective neuroscience The 'visceral sensation/pain neuromatrix' was outlined by numerous functional brain imaging studies assessing brain responses during oesophageal, rectal, and, to a lesser extent, gastric distension, mostly using barostat distension protocols. It consists of the cortical and subcortical regions described above. ${ }^{164}$ Moreover, a recent study confirmed the involvement of several distinct brainstem regions, including the PAG and RVM regions, in the processing of visceral sensation. ${ }^{165}$

It is, however, interesting that affective neuroscience is providing growing evidence for the hypothesis that interoceptive neurohumoural signals, especially from the viscera, and the brain regions processing such signals, are crucial in the generation and regulation of emotions and feelings. ${ }^{93,166-168}$ In a recent positron emission tomography study, Damasio et al. induced four different emotions in healthy volunteers using autobiographical memory scripts. Importantly, scanning only started when the subjects indicated that they actually started feeling the emotion. ${ }^{166}$ Virtually all regions that are known to process (visceral) sensory information (brainstem nuclei, insula, ACC, SII and orbitofrontal cortex (OFC)) were found to be involved in the feeling of emotional states, ${ }^{166}$ providing a neurobiological link between emotions and (visceral) sensation.

Several recent studies have compared brain responses during GI distension between FGID patients and healthy controls (reviewed in Refs ${ }^{33,91}$ ).

In IBS, abnormalities in brain processing of rectal sensory signals have mainly been found in the medial pain system (subregions of the ACC), providing evidence for abnormalities in the affective and/or cognitive dimension of the pain experience, which might be one aspect of a more generalized state of negative affectivity. Generally, these alterations in ACC activity can be explained in terms of altered visceral afferent input to the brain and/or abnormal affective or cognitive responses to visceral afferent signals at the level of the CNS itself. In a number of studies, IBS patients showed higher ACC activity during painful rectal distension when compared with healthy volunteers. ${ }^{8,169-171}$ Upregulation of visceral afferent input or increased ACC response (due to increased anticipation, hypervigilance or negative affective reaction to the visceral sensory stimulus) may account for these findings. However, in an equal number of other studies, lower or absent ACC activity was found as a brain response to rectal distension in IBS patients when compared with controls, ${ }^{172-175}$ which may be due to failure to activate descending antinociceptive pathways originating at the level of the ACC, ceiling effects or differential sensitization of the lateral, compared with the medial pain system in IBS.

It should be noted that heterogeneity in patient samples, stimuli applied and imaging methods used may at least partly account for the discrepancies in brain imaging findings in IBS. ${ }^{176}$ It is, for example, known that within the IBS group, a history of (childhood) sexual or physical abuse may alter brain responses to rectal distension. ${ }^{175}$ In conclusion, despite these discrepancies, there is a growing body of evidence supporting abnormal affective processing of visceral sensation in IBS patients. Furthermore, it has recently been shown that cognitive behavioural therapy (CBT) is associated with a reduction of baseline activity in the right subgenual ACC and the left medial temporal lobe (including the amygdala) of IBS patients, which was accompanied by improvements in GI symptoms, anxiety and worry. These brain activity changes may be the biological substrate of reduced attention to visceral stimuli or visceral-specific anxiety as a result of CBT in these patients. ${ }^{177}$

In $\mathrm{FD}$, brain imaging evidence is more sparse when compared with IBS. However, it was recently shown that in healthy volunteers, painful proximal gastric distension activates regions that are generally consistent with the visceral sensory 'neuromatrix', ${ }_{178,179}$ although there has been some debate regarding the role of somatosensory cortices. ${ }^{180,181}$ Functional dyspepsia patients who are hypersensitive to gastric distension showed similar activation of the lateral pain system (sensorimotor cortex) when compared with controls, although at far lower intragastric pressures and volumes (for similar pain or discomfort scores). ${ }^{182}$ This may provide a biological substrate for their hypersensitivity, but does not necessarily mean that central cognitive or affective processes are not involved (for an excellent account of this topic, see Ref. ${ }^{37}$ ). Furthermore, no activation of the medial pain 
system was found, which may again be explained in several ways, as described above. ${ }^{182}$

In a recent functional magnetic resonance imaging study, Phillips et al. showed that, in healthy volunteers, non-painful oesophageal stimulation is associated with greater neural activity in the dorsal ACC and the insula during fearful, compared with neutral emotional context produced by presentation of fearful or neutral facial expressions. ${ }^{183}$ Furthermore, discomfort, anxiety and activity in dorsal ACC and insula were significantly higher when high-intensity, compared with low-intensity fearful expressions were presented. ${ }^{183}$ The same group also found that selective and divided attention modulate the cerebral processing of oesophageal sensation in somatosensory and anterior cingulate cortices in a different way. ${ }^{43}$ These studies provide further evidence for an important influence of cognitive and affective factors on visceral sensation and its neurobiological correlates.

\section{FUTURE POTENTIAL TARGETS FOR TREATMENT OF FGID}

Recent progress in our understanding of sensory transduction of visceral afferents within the GI tract and spinal dorsal horn has resulted in potential new therapeutic targets being identified. Of these, the most promising targets on visceral afferents to reduce PS are the TRPV1 proton-activated receptor, the proteaseactivated receptor-2 via mast cell tryptase release, NMDA receptor subunit antagonists and VGSC, particularly Nav 1.8 and Nav 1.9, which have recently been shown to play an important role in the development of visceral hyperalgesia. ${ }^{205}$

Other potential targets include NGF acting at trk receptors which not only sensitize sensory neurones peripherally, but also mediate CS via increased gene transcription; prostanoid receptor antagonists acting peripherally and spinally at EP receptors and neurokinin receptor antagonists. Modulation of the descending facilitatory and inhibitory pathways also provides a novel area for therapeutic manipulation of visceral pain processing, with recent work suggesting a role for endogenous cannabinoid receptors. ${ }^{206}$ However, it must be recognized that these potential targets described above are aimed predominantly at modulating sensory visceral nociception and not the motor disturbances or altered brain processing of the stimuli such as serotonin agonists/antagonists or CRF antagonists. As our understanding of the pathophysiology of FGIDs increases, treatments will become targeted at specific underlying mechanisms and so provide more effective therapy than is currently available.

\section{SUMMARY}

An integrated biopsychosocial understanding of changes in intestinal sensory, motor and CNS activities is providing a conceptual model for FGID. In this model, higher neural centres are modulating peripheral intestinal sensory and motor activities and spinal sensory input, while the processing of these inputs by the brain can be influenced by psychological distress, which contributes to the generation of symptoms.

Several independent lines of evidence point towards an important role of psychosocial factors in FGID in general and an interaction between psychosocial factors and visceral sensitivity in particular. This yields support for a true biopsychosocial model of FGID, where we have to take the complex reciprocal relationship between psychosocial factors (including hypervigilance, stress, history of abuse and psychiatric comorbidity) and GI sensory and motor function (through their respective biological substrates) into account. This is necessary if we want to fully understand and elucidate the pathophysiology of FGID, as also in order to provide the best possible multidisciplinary care for this patient population that is often notoriously difficult to treat.

Visceral pain hypersensitivity is recognized as a characteristic feature in patients with FGID. Its pathophysiological basis is a combination of sensitized visceral afferent pathways, alterations in cortical processing of visceral afferent inputs and changes in descending modulatory inputs from the brainstem to the spinal cord and enteric neurones via the vagus nerve. However, the amount each step contributes to the overall perception of visceral pain hypersensitivity and hence symptom generation in individual patients still remains unclear.

With a continual increase in our knowledge of the mechanisms responsible for symptom generation in FGIDs, it is likely that the current classification system based on patients' symptoms will eventually change to be based on the underlying pathophysiological mechanisms. Greater understanding of the receptors (and eventually the genes) involved in each step will then ultimately lead to improved diagnosis and subsequent treatment of these disorders. However, as with all new therapeutic advancements, the promise of potential new treatments for visceral hypersensitivity in FGIDs will only be effective in the context of a patient-centred biopsychosocial plan of care with an effective patient-doctor relationship.

\section{ACKNOWLEDGEMENTS}

P. Anand thanks Dr A. Akbar and Mr P. Facer for helping with the text and figures. L. Van Oudenhove is 
a research fellow of the Research Foundation - Flanders (FWO-Vlaanderen).

\section{REFERENCES}

1 Talley NJ, Gabriel SE, Harmsen WS, Zinsmeister AR, Evans RW. Medical costs in community subjects with irritable bowel syndrome. Gastroenterology 1997; 109: 1736-41.

2 Fullerton S. Functional digestive disorders (FDD) in the year 2000 - economic impact. Eur I Surg Suppl 1998; 582: 62-4.

3 Mayer EA, Gebhart GF. Basic and clinical aspects of visceral hyperalgesia. Gastroenterology 1994; 107: 27193.

4 Sarkar S, Aziz Q, Woolf CJ, Hobson AR, Thompson DG. Contribution of central sensitization to the development of non-cardiac chest pain. Lancet 2000; 356: 1154-9.

5 Ritchie J. Pain from distension of the pelvic colon by inflating a balloon in the irritable colon syndrome. Gut 1973; 14: 125-32.

6 Salet GA, Samsom M, Roelofs JM, van Berge Henegouwen GP, Smout AJ, Akkermans LM. Responses to gastric distension in functional dyspepsia. Gut 1998; 42: 823-9.

7 Cook IJ, van Eeden A, Collins SM. Patients with irritable bowel syndrome have greater pain tolerance than normal subjects. Gastroenterology 1987; 93: 727-33.

8 Verne GN, Himes NC, Robinson ME et al. Central representation of visceral and cutaneous hypersensitivity in the irritable bowel syndrome. Pain 2003; 103: 99-110.

9 Blanchard EB, Scharff L, Schwarz SP, Suls JM, Barlow $\mathrm{DH}$. The role of anxiety and depression in the irritable bowel syndrome. Behav Res Ther 1990; 28: 401-5.

10 Locke R, Weaver AL, Joseph Melton L, Talley NJ. Psychosocial factors are linked to functional gastrointestinal disorders: a population based nested casecontrol study. Am J Gastroenterol 2004; 99: 350-7.

11 Mertz H, Pickens D, Fass R, Morgan V. Stress increases sensitivity to rectal distension in IBS but not controls, associated with greater limbic activation. Gastroenterology 2002; 122: A311.

12 Dickhaus B, Mayer EA, Firooz N et al. Irritable bowel syndrome patients show enhanced modulation of visceral perception by auditory stress. Am J Gastroenterol 2003; 98: $135-43$.

13 Gue M, Del Rio Lacheze C, Eutamene H, Theodorou V, Fioramonti J, Bueno L. Stress-induced visceral hypersensitivity to rectal distension in rats: role of CRF and mast cells. Neurogastroenterol Motil 1997; 9: 271-9.

14 Stam R, Croiset G, Akkermans LM, Wiegant VM. Sensitization of the colonic response to novel stress after previous stressful experience. Am J Physiol 1996; 271: R1270-3.

15 Geeraerts B, Vandenberghe J, Van Oudenhove L et al. Influence of experimentally induced anxiety on gastric sensorimotor function in man. Gastroenterology 2005; 129: 1437-44.

16 Coutinho SV, Plotsky PM, Sablad M et al. Neonatal maternal separation alters stress-induced responses to viscerosomatic nociceptive stimuli in rat. Am I Physiol Gastrointest Liver Physiol 2002; 282: G307-16.

17 Creed F, Guthrie E, Ratcliffe J et al. Does psychological treatment help only those patients with severe irritable bowel syndrome who also have a concurrent psychiatric disorder? Aust N Z J Psychiatry 2005; 39: 807-15.

18 Drossman DA. Do psychosocial factors define symptom severity and patient status in irritable bowel syndrome? Am J Med 1999; 107: 41S-50S.

19 Al-Chaer ED, Kawasaki M, Pasricha PJ. A new model of chronic visceral hypersensitivity in adult rats induced by colon irritation during postnatal development. Gastroenterology 2000; 119: 1276-85.

20 Spiller RC, Jenkins D, Thornley JP et al. Increased rectal mucosal enteroendocrine cells, $\mathrm{T}$ lymphocytes, and increased gut permeability following acute campylobacter enteritis and in post-dysenteric irritable bowel syndrome. Gut 2000; 47: 804-11.

21 Spiller RC. Postinfectious irritable bowel syndrome. Gastroenterology 2003; 124: 1662-71.

22 Longstreth GF, Yao J. Irritable bowel syndrome and surgery: a multivariate analysis. Gastroenterology 2004; 126: 1665-73.

23 Gwee KA, Graham JC, McKendrick MW et al. Psychometric scores and persistence of irritable bowel after infectious diarrhoea. Lancet 1996; 347: 150-3.

24 Gwee KA, Leong YL, Graham C et al. The role of psychological and biological factors in postinfective gut dysfunction. Gut 1999; 44: 400-6.

25 Tack J, Bisschops R, Sarnelli G. Pathophysiology and treatment of functional dyspepsia. Gastroenterology 2004; 127: 1239-55.

26 Tack J, Caenepeel P, Fischler B, Piessevaux H, Janssens J. Symptoms associated with hypersensitivity to gastric distention in functional dyspepsia. Gastroenterology 2001; 121: 526-35.

27 Tack J, Piessevaux H, Coulie B, Caenepeel P, Janssens J. Role of impaired gastric accommodation to a meal in functional dyspepsia. Gastroenterology 1998; 115: 134652.

28 Quigley EMM. Review article: gastric emptying in functional gastrointestinal disorders. Aliment Pharmacol Ther 2004; 20: 56-60.

29 Fischler B, Tack J, De Gucht V et al. Heterogeneity of symptom pattern, psychosocial factors, and pathophysiological mechanisms in severe functional dyspepsia. Gastroenterology 2003; 124: 903-10.

30 Porcelli P, Affatati V, Bellomo A, De Carne M, Todarello $\mathrm{O}$, Taylor GJ. Alexithymia and psychopathology in patients with psychiatric and functional gastrointestinal disorders. Psychother Psychosom 2004; 73: 84-91.

31 Budavari AI, Olden KW. Psychosocial aspects of functional gastrointestinal disorders. Gastroenterol Clin North Am 2003; 32: 477-506.

32 Castillo EJ, Camilleri $M$, Locke GR, Burton DD, Stephens DA, Geno DM, Zinsmeister AR. A communitybased, controlled study of the epidemiology and pathophysiology of dyspepsia. Clin Gastroenterol Hepatol 2004; 2: 985-96.

33 Van Oudenhove L, Demyttenaere K, Tack J, Aziz Q. Central nervous system involvement in functional gastrointestinal disorders. Best Pract Res Clin Gastroenterol 2004; 18: 663-80.

34 Whitehead WE, Palsson O, Jones KR. Systematic review of the comorbidity of irritable bowel syndrome with other disorders: what are the causes and implications? Gastroenterology 2002; 122: 1140-56. 
35 Drossman DA, Camilleri M, Mayer EA, Whitehead WE. AGA technical review on irritable bowel syndrome. Gastroenterology 2002; 123: 2108-31.

36 Locke GR, Lin S-C, Talley NJ. Psychiatric disease and functional GI disorders in the community: more evidence for a casual link? Am J Gastroenterol 2005; 100: 248-9.

37 Naliboff BD, Mayer EA. Brain imaging in IBS: drawing the line between cognitive and non-cognitive processes. Gastroenterology 2006; 130: 267-70.

38 Lydiard RB. Irritable bowel syndrome, anxiety, and depression: what are the links? J Clin Psychiatry 2001; 62 (Suppl. 8): 38-45.

39 Critchley HD, Wiens S, Rotshtein P, Ohman A, Dolan RJ. Neural systems supporting interoceptive awareness. Nat Neurosci 2004; 7: 189-95.

40 Ploghaus A, Tracey I, Gati JS et al. Dissociating pain from its anticipation in the human brain. Science 1999; 284: 1979-81.

41 Keogh E, Cochrane M. Anxiety sensitivity, cognitive biases, and the experience of pain. J Pain 2002; 3: 320-9.

42 Petrovic P, Ingvar M. Imaging cognitive modulation of pain processing. Pain 2002; 95: 1-5.

43 Gregory LJ, Yaguez L, Williams SCR et al. Cognitive modulation of the cerebral processing of human oesophageal sensation using functional magnetic resonance imaging. Gut 2003; 52: 1671-7.

44 Yágüez L, Coen S, Gregory LJ et al. Brain response to visceral aversive conditioning: a functional magnetic resonance imaging study. Gastroenterology 2005; 128: 1819-29.

45 Ochsner KN, Ludlow DH, Knierim K et al. Neural correlates of individual differences in pain-related fear and anxiety. Pain 2006; 120: 69-77.

46 Talley NJ, Howell S, Poulton R. The irritable bowel syndrome and psychiatric disorders in the community: is there a link? Am J Gastroenterol 2001; 96: 1072-79.

47 Blakely RD. Physiological genomics of antidepressant targets: keeping the periphery in mind. I Neurosci 2001; 21: 8319-23.

48 Costigan M, Woolf CJ. Pain: molecular mechanisms. I Pain 2000; 1: 35-44.

49 Woolf CJ, Salter MW. Neuronal plasticity: increasing the gain in pain. Science 2000; 288: 1765-9.

50 Yiangou Y, Facer P, Baecker PA et al. ATP-gated ion channel $\mathrm{P} 2 \mathrm{X}(3)$ is increased in human inflammatory bowel disease. Neurogastroenterol Motil 2001; 13: 365-9.

51 Yiangou Y, Facer P, Dyer NH et al. Vanilloid receptor 1 immunoreactivity in inflamed human bowel. Lancet 2001; 357: 1338-9.

52 Yiangou Y, Facer P, Ford A et al. Capsaicin receptor VR1 and ATP-gated ion channel $\mathrm{P}_{2} \mathrm{X}_{3}$ in human urinary bladder. BJU Int 2001; 87: 774-9.

53 Yiangou Y, Facer P, Smith JA et al. Increased acid-sensing ion channel ASIC-3 in inflamed human intestine. Eur J Gastroenterol Hepatol 2001; 13: 891-6.

54 Woolf CJ. Phenotypic modification of primary sensory neurones: the role of nerve growth factor in the production of persistent pain. Philos Trans $R$ Soc Lond B Biol Sci 1996; 351: 441-8.

55 Sciberras DG, Goldenberg MM, Bolognese JA, James I, Baber NS. Inflammatory responses to intradermal injection of platelet activating factor, histamine and prosta- glandin E2 in healthy volunteers: a double blind investigation. Br J Clin Pharmacol 1987; 24: 753-61.

56 Seibert K, Zhang Y, Leahy K et al. Pharmacological and biochemical demonstration of the role of cyclooxygenase 2 in inflammation and pain. Proc Natl Acad Sci USA 1994; 91: 12013-7.

57 Chan C, Facer P, Davis J, Smith G, Egerton J, Bountra C, Williams N, Anand P. Sensory fibres expressing capsaicin receptor TRPV1 in patients with rectal hypersensitivity and faecal urgency. Lancet 2003; 361: 385-91.

58 Tympanidis $\mathrm{P}$, Casula MA, Yiangou Y, Terenghi G, Dowd P, Anand P. Increased vanilloid receptor VR1 innervation in vulvodynia. Eur I Pain 2004; 8: 129-33.

59 Matthews PJ, Aziz Q, Facer P, Davis JB, Thompson DG, Anand P. Increased capsaicin receptor TPRV1 nerve fibres in the inflamed human oesophagus. Eur I Gastroenterol Hepatol 2004; 16: 897-902.

60 Yoshida N, Uchiyama K, Kuroda M et al. Interleukin-8 expression in the esophageal mucosa of patients with gastroesophageal reflux disease. Scand I Gastroenterol 2004; 39: 816-22.

61 Woolf CJ. Evidence for a central component of post-injury pain hypersensitivity. Nature 1983; 306: 686-8.

62 Woolf CJ. Generation of acute pain: central mechanisms. Br Med Bull 1991; 47: 523-33.

63 Woolf CJ. An overview of the mechanisms of hyperalgesia. Pulm Pharmacol 1995; 8: 161-7.

64 Woolf CJ, Thompson SW. The induction and maintenance of central sensitization is dependent on N-methyl$D$-aspartic acid receptor activation; implications for the treatment of post-injury pain hypersensitivity states. Pain 1991; 44: 293-9.

65 Ji RR, Woolf CJ. Neuronal plasticity and signal transduction in nociceptive neurones: implications for the initiation and maintenance of pathological pain. Neurobiol Dis 2001; 8: 1-10.

66 Woolf CJ, Costigan M. Transcriptional and posttranslational plasticity and the generation of inflammatory pain. Proc Natl Acad Sci USA 1999; 96: 7723-30.

67 Neumann S, Doubell TP, Leslie T, Woolf CJ. Inflammatory pain hypersensitivity mediated by phenotypic switch in myelinated primary sensory neurones. Nature 1996; 384: 360-4.

68 Woolf CJ, King AE. Dynamic alterations in the cutaneous mechanoreceptive fields of dorsal horn neurones in the rat spinal cord. J Neurosci 1990; 10: 2717-26.

69 Simone DA, Baumann TK, Collins JG, LaMotte RH. Sensitization of cat dorsal horn neurones to innocuous mechanical stimulation after intradermal injection of capsaicin. Brain Res 1989; 486: 185-9.

70 Woolf CJ, Wall PD. Relative effectiveness of C primary afferent fibers of different origins in evoking a prolonged facilitation of the flexor reflex in the rat. J Neurosci 1986; 6: $1433-42$.

71 Gracely RH, Lynch SA, Bennett GJ. Painful neuropathy: altered central processing maintained dynamically by peripheral input. Pain 1992; 51: 175-94.

72 Simone DA, Sorkin LS, Oh U et al. Neurogenic hyperalgesia: central neural correlates in responses of spinothalamic tract neurones. I Neurophysiol 1991; 66: 22846.

73 Dougherty PM, Willis WD. Enhanced responses of spinothalamic tract neurones to excitatory amino acids 
accompany capsaicin-induced sensitization in the monkey. J Neurosci 1992; 12: 883-94.

74 Hylden JL, Nahin RL, Traub RJ, Dubner R. Expansion of receptive fields of spinal lamina I projection neurones in rats with unilateral adjuvant-induced inflammation: the contribution of dorsal horn mechanisms. Pain 1989; 37: 229-43.

75 Schaible HG, Grubb BD, Neugebauer V, Oppmann M. The effects of NMDA antagonists on neuronal activity in cat spinal cord evoked by acute inflammation in the knee joint. Eur J Neurosci 1991; 3: 981-991.

76 Willis WD. Long-term potentiation in spinothalamic neurones. Brain Res Brain Res Rev 2002; 40: 202-14.

77 LaMotte RH, Lundberg LE, Torebjork HE. Pain, hyperalgesia and activity in nociceptive $\mathrm{C}$ units in humans after intradermal injection of capsaicin. I Physiol 1992; 448: 749-64.

78 Simone DA, Baumann TK, LaMotte RH. Dose-dependent pain and mechanical hyperalgesia in humans after intradermal injection of capsaicin. Pain 1989; 38: 99-107.

79 Koltzenburg M, Lundberg LE, Torebjork HE. Dynamic and static components of mechanical hyperalgesia in human hairy skin. Pain 1992; 51: 207-19.

80 Treede RD, Meyer RA, Raja SN, Campbell JN. Peripheral and central mechanisms of cutaneous hyperalgesia. Prog Neurobiol 1992; 38: 397-421.

81 Staud R, Cannon RC, Mauderli AP, Robinson ME, Price DD, Vierck CJ Jr. Temporal summation of pain from mechanical stimulation of muscle tissue in normal controls and subjects with fibromyalgia syndrome. Pain 2003; 102: 87-95.

82 Schaible HG, Ebersberger A, Von Banchet GS. Mechanisms of pain in arthritis. Ann N Y Acad Sci 2002; 966: 343-54

83 Stubhaug A, Breivik H, Eide PK, Kreunen M, Foss A. Mapping of punctuate hyperalgesia around a surgical incision demonstrates that ketamine is a powerful suppressor of central sensitization to pain following surgery. Acta Anaesthesiol Scand 1997; 41: 1124-32.

84 Eliav E, Teich S, Benoliel R et al. Large myelinated nerve fiber hypersensitivity in oral malignancy. Oral Surg Oral Med Oral Pathol Oral Radiol Endod 2002; 94: 45-50.

85 Campbell JN, Raja SN, Meyer RA, Mackinnon SE. Myelinated afferents signal the hyperalgesia associated with nerve injury. Pain 1988; 32: 89-94.

86 Burstein R, Cutrer MF, Yarnitsky D. The development of cutaneous allodynia during a migraine attack clinical evidence for the sequential recruitment of spinal and supraspinal nociceptive neurones in migraine. Brain 2000; 123: 1703-9.

87 Woolf CJ, Mannion RJ. Neuropathic pain: aetiology, symptoms, mechanisms, and management. Lancet 1999; 353: 1959-64.

88 Gracely RH, Petzke F, Wolf JM, Clauw DJ. Functional magnetic resonance imaging evidence of augmented pain processing in fibromyalgia. Arthritis Rheum 2002; 46: 1333-43.

89 Burstein R, Yarnitsky D, Goor-Aryeh I, Ransil BJ, Bajwa $\mathrm{ZH}$. An association between migraine and cutaneous allodynia. Ann Neurol 2000; 47: 614-24.

90 Watkins LR, Maier SF. The pain of being sick: implications of immune-to-brain communication for understanding pain. Annu Rev Psychol 2000; 51: 29-57.
91 Jones MP, Dilley JB, Drossman D, Crowell MD. Brain-gut connections in functional GI disorders: anatomic and physiologic relationships. Neurogastroenterol Motil 2006; 18: 91-103.

92 Almeida TF, Roizenblatt S, Tufik S. Afferent pain pathways: a neuroanatomical review. Brain Res 2004; 1000: 40-56.

93 Ongur D, Price JL. The organization of networks within the orbital and medial prefrontal cortex of rats, monkeys and humans. Cereb Cortex 2000; 10: 206-219.

94 Cervero F, Wolstencroft JH. A positive feedback loop between spinal cord nociceptive pathways and antinociceptive areas of the cat's brain stem. Pain 1984; 20: 12538.

95 Cervero F, Tattersall J. Cutaneous receptive fields of soamtic and viscerosomatic neurones in the thoracic spinal cord of the cat. I Comp Neurol 1985; 237: 32532.

96 Tattersall JE, Cervero F, Lumb BM. Viscerosomatic neurones in the lower thoracic spinal cord of the cat: excitations and inhibitions evoked by splanchnic and somatic nerve volleys and by stimulation of brain stem nuclei. I Neurophysiol 1986; 56: 1411-23.

97 Haines DE, Milhailoff GA, Yezierski RP. The spinal cord. In: Haines DE, ed. Fundamental Neuroscience, Vol. 129. New York: Churchill, 1997: 142-58.

98 Foreman RD. Spinal and supra-spinal processing of nociceptive inputs from the urinary bladder and somatic receptive fields. In: Mayer EA, Radbould $\mathrm{H}$, eds. Basic and Clinical Aspects of Chronic Abdominal Pain. San Diego: Elsevier Science Publishers, 1993.

99 Payne WW, Poulton EP. Experiments on visceral sensation. Part II. J Physiol Lond 1928; 65: 157-72.

100 Basbaum A, Fields H. Endogenous pain control systems: brainstem spinal pathways and endorphin circuitry. Annu Rev Neurosci 1984; 7: 309-38.

101 Millan M. Descending control of pain. Prog Neurobiol 2002; 66: 355-474.

102 Fields H. State-dependent opioid control of pain. Nat Rev Neurosci 2004; 5: 565-75.

103 Giesler GJ Jr, Liebeskind JC. Inhibition of visceral pain by electrical stimulation of the periaqueductal gray matter. Pain 1976; 2: 43-8.

104 Cervero F, Lumb B, Tattersall J. Supraspinal loops that mediate visceral inputs to thoracic spinal cord neurones in the cat. Neurosci Lett 1985; 56: 189-94.

105 Ness TJ, Gebhart GF. Quantitative comparison of inhibition of visceral and cutaneous spinal nociceptive transmission from the midbrain and medulla in the rat. I Neurophysiol 1987; 58: 850-65.

106 Zhuo M, Gebhart GF. Facilitation and attention of a visceral nociceptive reflex from the rostroventral medulla in the rat. Gastroenterol 2002; 122: 1007-19.

107 Coutinho SV, Urban MO, Gebhart GF. The role of CNS NMDA receptors and nitric oxide in visceral hyperalgesia. Eur J Pharmacol 2001; 429: 319-25.

108 Jasmin L, Rabkin SD, Granato A, Boudah A, Ohara PT. Analgesia and hyperalgesia from GABA-mediated modulation of the cerebral cortex. Nature 2003; 424: 316-20.

109 Rosen A, Lundeberg T, Bytner B, Nylander I. Central changes in nociceptin dynorphin B and Met-enkephalinArg-Phe in different models of nociception. Brain Res 2000; 857: 212-8. 
110 Collins SM. The immunomodulation of enteric neuromuscular function: implications for motility and inflammatory disorders. Gastroenterology 1996; 111: 1683-99.

111 Al Chaer ED, Lawand NB, Westlund KN, Willis WD. Visceral nociceptive input into the ventral posterolateral nucleus of the thalamus: a new function for the dorsal column pathway. I Neurophysiol 1996; 76: 2661-74.

112 Gwee KA, Collins SM, Read NW et al. Increased rectal mucosal expression of interleukin lbeta in recently acquired post-infectious irritable bowel syndrome. Gut 2003; 52: 523-6.

113 Barbara G, Stanghellini V, De Giorgio R et al. Activated mast cells in proximity to colonic nerves correlate with abdominal pain in irritable bowel syndrome. Gastroenterology 2004; 126: 693-702.

114 Suzuki R, Furuno T, McKay DM et al. Direct neuritemast cell communication in vitro occurs via the neuropeptide substance P. I Immunol 1999; 163: 2410-5.

115 van der Kleij HP, Ma D, Redegeld FA, Kraneveld AD, Nijkamp FP, Bienenstock J. Functional expression of neurokinin 1 receptors on mast cells induced by IL-4 and stem cell factor. I Immunol 2003; 171: 2074-9.

116 Barbara G, De Giorgio R, Stanghellini V, Cremon C, Corinaldesi R. A role for inflammation in irritable bowel syndrome? Gut 2002; 51 (Suppl. 1): i41-4.

117 Coutinho SV, Su X, Sengupta JN, Gebhart G. Role of sensitised pelvic nerve afferents from the inflamed rat colon in the maintenance of visceral hyperalgesia. Prog Brain Res 2000; 129: 375-87.

118 Blackshaw LA, Gebhart GF. The pharmacology of gastrointestinal nociceptive pathways. Curr Opin Pharmacol 2002; 2: 642-9.

119 Caterina MJ, Schumacher MA, Tominaga M, Rosen TA, Levine JD, Julius D. The capsaicin receptor: a heat-activated ion channel in the pain pathway. Nature 1997; 389: 816-824.

120 Mezey E, Toth ZE, Cortright DN et al. Distribution of mRNA for vanilloid receptor subtype 1 (VR1), and VR1like immunoreactivity, in the central nervous system of the rat and human. Proc Natl Acad Sci USA 2000; 97: 3655-60.

121 Zygmunt PM, Petersson J, Andersson DA et al. Vanilloid receptors on sensory nerves mediate the vasodilator action of anandamide. Nature 1999; 400: 452-7.

122 Lysy J, Sistiery-Ittah M, Israelit Y et al. Topical capsaicin - a novel and effective treatment for idiopathic intractable pruritus ani: a randomised, placebo controlled, crossover study. Gut 2003; 52: 1323-6.

123 Bar KJ, Facer P, Williams NS, Tam PK, Anand P. Glialderived neurotrophic factor in human adult and fetal intestine and in Hirschsprung's disease. Gastroenterology 1997; 112: 1381-5.

124 Bhat YM, Bielefeldt K. Capsaicin receptor (TRPV1) and non-erosive reflux disease. Eur I Gastroenterol Hepatol 2006; 18: 263-70.

125 Bortolotti M, Coccia G, Grossi G, Miglioli M. The treatment of functional dyspepsia with red pepper. Aliment Pharmacol Ther 2002; 16: 1075-82.

126 Drewes AM, Schipper K-P, Dimcevski G et al. Gut pain and hyperalgesia induced by capsaicin: a human experimental model. Pain 2003; 104: 333-41.
127 Schmidt B, Hammer J, Holzer P, Hammer HF. Chemical nociception in the jejunum induced by capsaicin. Gut 2004; 53: 1109-16.

128 di Mola FF, Friess H, Zhu ZW et al. Nerve growth factor and Trk high affinity receptor (TrkA) gene expression in inflammatory bowel disease. Gut 2000; 46: 670-9.

129 Ji R-R, Samad TA, Jin S-X, Schmoll R, Woolf CJ. p38 MAPK Activation by NGF in primary sensory neurones after inflammation increases TRPV1 levels and maintains heat hyperalgesia. Neuron 2002; 36: 57-68.

130 Premkumar LS, Ahern GP. Induction of vanilloid receptor channel activity by protein kinase C. Nature 2000; 408: 985-90.

131 Waldmann R, Champigny G, Bassilana F, Heurteaux C, Lazdunski $M$. A proton-gated cation channel involved in acid-sensing. Nature 1997; 386: 173-7.

132 North RA, Barnard EA. Nucleotide receptors. Curr Opin Neurobiol 1997; 7: 346-57.

133 Wood JN. Recent advances in understanding molecular mechanisms of primary afferent activation. Gut 2004; 53: ii9-12.

134 Catterall WA. Cellular and molecular biology of voltagegated sodium channels. Physiol Rev 1992; 72: S15-48.

135 Cervero F. Sensory innervation of the viscera: peripheral basis of visceral pain. Physiol Rev 1994; 74: 95-138.

136 Gebhart GFN, Ness TJ. Visceral pain: a review of experimental studies. Pain 1990; 41: 167-234.

137 Gebhart GF, Ness TJ. Central mechanisms of visceral pain. Can J Physiol Pharmacol 1991; 69: 627-34.

138 Gebhart GF. Pathobiology of visceral pain: molecular mechanisms and therapeutic implications IV. Visceral afferent contributions to the pathobiology of visceral pain. Am J Physiol Gastrointest Liver Physiol 2000; 278: G834-8

139 Mayer EA, Collins SM. Evolving pathophysiologic models of functional gastrointestinal disorders. Gastroenterology 2002; 122: 2032-48.

140 Sarkar S, Hobson AR, Furlong PL, Woolf CJ, Thompson DG, Aziz Q. Central neural mechanisms mediating human visceral hypersensitivity. Am I Physiol Gastrointest Liver Physiol 2001; 281: G1196-202.

141 Willert RP, Woolf CJ, Hobson AR, Delaney C, Thompson DG, Aziz Q. The Development and maintenance of human visceral pain hypersensitivity is dependent on the N-methly-D-aspartate receptor. Gastroenterology 2004; 126: 683-692.

142 Garrison DW, Chandler MJ, Foreman RD. Viscerosomatic convergence onto feline spinal neurones from esophagus, heart and stomach fields: effects of inflammation. Pain 1992; 49: 373-82.

143 Giamberardino MA, Dalal A, Valente R, Vecchiet L. Changes in activity of spinal cells with muscular input in rats with referred muscular hyperalgesia from ureteral calculosis. Neurosci Lett 1996; 203: 89-92.

144 Miranda A, Peles S, Rudolph C, Shaker R, Sengupta JN. Altered visceral sensation in response to somatic pain in the rat. Gastroenterology 2004; 126: 1082-9.

145 Zhai QZ, Traub RJ. Differential effects of N-methyl-Daspartate receptor blockade on nociceptive somatic and visceral reflexes. Pain 1999; 83: 321-9.

146 Traub RJ, Zhai Q, Ji Y, Kovalenko M. NMDA receptor antagonists attenuate noxious and nonnoxious colorectal 
distention-induced Fos expression in the spinal cord and the visceromotor reflex. Neuroscience 2002; 113: 205-11.

147 Labus JS, Bolus R, Chang L et al. The visceral sensitivity index: development and validation of a gastrointestinal symptom-specific anxiety scale. Aliment Pharmacol Ther 2004; 20: 89-97.

148 Schwetz I, Bradesi S, McRoberts JA et al. Delayed stressinduced colonic hypersensitivity in male Wistar rats: role of neurokinin-1 and corticotropin-releasing factor-1 receptors. Am I Physiol Gastrointest Liver Physiol 2004; 286: G683-91.

149 Lechner SM, Curtis AL, Brons R, Valentino RJ. Locus coeruleus activation by colon distention: role of corticotropin-releasing factor and excitatory amino acids. Brain Res 1997; 756: 114-24.

150 Lembo T, Plourde V, Shui Z et al. Effects of the corticotropin-releasing factor (CRF) on rectal afferent nerves in humans. Neurogastroenterol Motil 1996; 8: 9-18.

151 Sagami Y, Shimada Y, Tayama J et al. Effect of a corticotropin releasing hormone receptor antagonist on colonic sensory and motor function in patients with irritable bowel syndrome. Gut 2004; 53: 958-64.

152 Drossman DA. Sexual and physical abuse and gastrointestinal illness. Scand I Gastroenterol Suppl 1995; 208: 90-6.

153 Van Oudenhove L, Vandenberghe J, Geeraerts B, Vos R, Demyttenaere K, Tack J. Influence of anxiety on gastric sensorimotor function in functional dyspepsia. Gastroenterology 2005; 128 (Suppl. 2): A135-6.

154 Geeraerts B, Van Oudenhove L, Fischler B et al. The association between gastric sensorimotor function and abuse history in functional dyspepsia. Gastroenterology 2005; 128 (Suppl. 2): A339.

155 Ringel Y, Whitehead WE, Toner BB et al. Sexual and physical abuse are not associated with rectal hypersensitivity in patients with irritable bowel syndrome. Gut 2004; 53: 838-42.

156 Raphael KG. Childhood abuse and pain in adulthood: more than a modest relationship? Clin I Pain 2005; 21: 371-3.

157 Sykes MA, Blanchard EB, Lackner J, Keefer L, Krasner S. Psychopathology in irritable bowel syndrome: support for a psychophysiological model. J Behav Med 2003; 26: 36172.

158 Whorwell PJ, Prior A, Faragher EB. Controlled trial of hypnotherapy in the treatment of severe refractory irritable-bowel syndrome. Lancet 1984; 2: 1232-4.

159 Guthrie E, Creed F, Dawson D, Tomenson B. A controlled trial of psychological treatment for the irritable bowel syndrome. Gastroenterology 1991; 100: 450-7.

160 Gonsalkorale WM, Miller V, Afzal A, Whorwell PJ. Long term benefits of hypnotherapy for irritable bowel syndrome. Gut 2003; 52: 1623-9.

161 Urban MO, Gebhart GF. Supraspinal contributions to hyperalgesia. Proc Natl Acad Sci USA 1999; 96: 768792.

162 Sandkuhler J, Gebhart GF. Characterization of inhibition of a spinal nociceptive reflex by stimulation medially and laterally in the midbrain and medulla in the pentobarbital-anesthetized rat. Brain Res 1984; 305: 67-76.

163 Mayer EA. Spinal and supraspinal modulation of visceral sensation. Gut 2000; 47: iv69-72, discussion iv76.
164 Derbyshire SWG. A systematic review of neuroimaging data during visceral stimulation. Am I Gastroenterol 2003; 98: 12-20.

165 Dunckley P, Wise RG, Fairhurst M, Hobden P, Aziz Q, Chang L, Tracey I. A comparison of visceral and somatic pain processing in the human brainstem using functional magnetic resonance imaging. J Neurosci 2005; 25: 7333 41.

166 Damasio AR, Grabowski TJ, Bechara A et al. Subcortical and cortical brain activity during the feeling of self-generated emotions. Nat Neurosci 2000; 3: 1049-56.

167 Damasio AR. Looking for Spinoza: Joy, Sorrow and the Feeling Brain. Orlando: Harcourt, 2003: 27-126.

168 Phan KL, Wager TD, Taylor SF, Liberzon I. Functional neuroimaging studies of human emotions. CNS Spectr 2004; 9: 258-66.

169 Mayer EA, Berman S, Suyenobu B et al. Differences in brain responses to visceral pain between patients with irritable bowel syndrome and ulcerative colitis. Pain 2005; 115: 398-409.

170 Naliboff BD, Derbyshire SWG, Munakata J et al. Cerebral activation in patients with irritable bowel syndrome and control subjects during rectosigmoid stimulation. Psychosom Med 2001; 63: 365-75.

171 Mertz H, Morgan V, Tanner G, Pickens D, Price R, Shyr $\mathrm{Y}$, Kessler R. Regional cerebral activation in irritable bowel syndrome and control subjects with painful and nonpainful rectal distention. Gastroenterology 2000; 118: 842-8.

172 Wilder-Smith CH, Schindler D, Lovblad K, Redmond SM, Nirkko A. Brain functional magnetic resonance imaging of rectal pain and activation of endogenous inhibitory mechanisms in irritable bowel syndrome patient subgroups and healthy controls. Gut 2004; 53: 1595-1601.

173 Andresen V, Bach DR, Poellinger A et al. Brain activation responses to subliminal or supraliminal rectal stimuli and to auditory stimuli in irritable bowel syndrome. Neurogastroenterol Motil 2005; 17: 827-37.

174 Kwan CL, Diamant NE, Pope G, Mikula K, Mikulis DJ, Davis KD. Abnormal forebrain activity in functional bowel disorder patients with chronic pain. Neurology 2005; 65: 1268-77.

175 Ringel Y, Drossman DA, Turkington TG et al. Regional brain activation in response to rectal distension in patients with irritable bowel syndrome and the effect of a history of abuse. Dig Dis Sci 2003; 48: 1774-81.

176 Hobson AR, Aziz Q. Brain imaging and functional gastrointestinal disorders: has it helped our understanding? Gut 2004; 53: 1198-206.

177 Lackner JM, Lou Coad M, Mertz HR et al. Cognitive therapy for irritable bowel syndrome is associated with reduced limbic activity, GI symptoms, and anxiety. Behav Res Ther 2006; 44: 621-38.

178 Vandenberghe J, Dupont P, Fischler B, Persoons P, Tack J. Regional brain activation during proximal stomach distention in man: a PET study. Gastroenterology 2005; 128: 564-73.

179 Lu C-L, Wu Y-T, Yeh T-C et al. Neuronal correlates of gastric pain induced by fundus distension: a 3T-fMRI study. Neurogastroenterol Motil 2004; 16: 575-87.

$180 \mathrm{Lu} \mathrm{C}-\mathrm{L}$, Chang F-Y, Hsieh J-C. Is somatosensory cortex activated during proximal stomach stimulation and the 
role of insula in visceral pain. Gastroenterology 2005; 128: $1529-30$.

181 Van Oudenhove L, Dupont P, Vandenberghe J, Geeraerts B, Tack J. Is somatosensory cortex activated during proximal stomach stimulation and the role of insula in visceral pain - Reply to Lu et al. Gastroenterology 2005; 128: 1530-1.

182 Vandenberghe J, Dupont P, Persoons P, Demyttenaere K, Tack J. Regional cerebral blood flow during gastric balloon distention in functional dyspepsia. Gastroenterology 2003; 124 (Suppl. 2): A29.

183 Phillips M, Gregory L, Cullen S et al. The effect of negative emotional context on neural and behavioural responses to oesophageal stimulation. Brain 2003; 126: 669-684.

184 Whitehead WE, Palsson OS. Is rectal pain sensitivity a biological marker for irritable bowel syndrome: psychological influences on pain perception. Gastroenterology 1998; 115: 1263-71.

185 Sarkar S, Hobson AR, Hughes A et al. The prostaglandin E2 receptor-1 (EP-1) mediates acid-induced visceral pain hypersensitivity in humans. Gastroenterology 2003; 124: $18-25$.

186 Malmberg AB, Yaksh TL. Antinociceptive actions of spinal nonsteroidal anti-inflammatory agents on the formalin test in the rat. $J$ Pharmacol Exp Ther 1992; 263: 136-46.

187 Malmberg AB, Yaksh TL. Antinociception produced by spinal delivery of the $\mathrm{S}$ and $\mathrm{R}$ enantiomers of flurbiprofen in the formalin test. Eur I Pharmacol 1994; 256: 205-9.

188 Willingale HL, Gardiner NJ, McLymont N, Giblett S, Grubb BD. Prostanoids synthesized by cyclo-oxygenase isoforms in rat spinal cord and their contribution to the development of neuronal hyperexcitability. Br I Pharmacol 1997; 122: 1593-604.

189 Yaksh TL, Dirig DM, Conway CM, Svensson C, Luo ZD, Isakson PC. The acute antihyperalgesic action of nonsteroidal, anti-inflammatory drugs and release of spinal prostaglandin E2 is mediated by the inhibition of constitutive spinal cyclooxygenase-2 (COX-2) but not COX1. J Neurosci 2001; 21: 5847-53.

190 Svensson CI, Yaksh TL. The spinal phospholipase-cyclooxygenase-prostanoid cascade in nociceptive processing. Annu Rev Pharmacol Toxicol 2002; 42: 553-83.

191 Willert RP, Delaney C, Hobson AR, Thompson DG, Woolf CJ, Aziz Q. Constitutive cyclo-oxygenase-2 does not contribute to the development of human visceral pain hypersensitivity. Eur J Pain 2006; 10: 487-94.

192 Vanegas H, Schaible HG. Prostaglandins and cyclooxygenases [correction of cycloxygenases] in the spinal cord. Prog Neurobiol 2001; 64: 327-63.

193 Traub RJ. The spinal contribution of substance P to the generation and maintenance of inflammatory hyperalgesia in the rat. Pain 1996; 67: 151-61.

194 Mantyh PW, Rogers SD, Honore P et al. Inhibition of hyperalgesia by ablation of lamina I spinal neurones expressing the substance P receptor. Science 1997; 278: 275-9.

195 Nichols ML, Allen BJ, Rogers SD et al. Transmission of chronic nociception by spinal neurones expressing the substance P receptor. Science 1999; 286: 1558-61.

196 Laird JMA, Roza C, De Felipe C, Hunt SP, Cervero F. Role of central and peripheral tachykinin NK1 receptors in capsaicin-induced pain and hyperalgesia in mice. Pain 2001; 90: 97-103.

197 Okano S, Nagaya H, Ikeura Y, Natsugari H, Inatomi N. Effects of TAK-637, a novel neurokinin-1 receptor antagonist, on colonic function in vivo. I Pharmacol Exp Ther 2001; 298: 559-64.

198 Greenwood-Van Meerveld B, Gibson MS, Johnson AC, Venkova K, Sutkowski-Markmann D. NK1 receptormediated mechanisms regulate colonic hypersensitivity in the guinea pig. Pharmacol Biochem Behav 2003; 74: 1005-13.

199 Boyce S, Hill R. Discrepant results from preclinical and clinical studies on the potential of substance $\mathrm{P}$ receptor antagonist compounds as analgesics. In: Devor $M$, Rowbotham MC, Wiesenfeld-Hallin Z, eds. Proceedings of the 9th World Congress on Pain. Progress in Pain Research and Management, Vol. 16. Seattle: IASP Press, 2000.

200 De Felipe C, Herrero JF, O'Brien JA et al. Altered nociception, analgesia and aggression in mice lacking the receptor for substance P. Nature 1998; 392: 3947.

201 Zimmer A, Zimmer AM, Baffi J et al. Hypoalgesia in mice with a targeted deletion of the tachykinin 1 gene. Proc Natl Acad Sci USA 1998; 95: 2630-5.

202 Perry MJ, Lawson SN. Differences in expression of oligosaccharides, neuropeptides, carbonic anhydrase and neurofilament in rat primary afferent neurones retrogradely labelled via skin, muscle or visceral nerves. Neuroscience 1998; 85: 293-310.

203 Brown JL, Liu H, Maggio JE, Vigna SR, Mantyh PW, Basbaum AI. Morphological characterization of substance $\mathrm{P}$ receptor-immunoreactive neurones in the rat spinal cord and trigeminal nucleus caudalis. I Comp Neurol 1995; 356: 327-44.

204 Willert RP, Delaney C, Hobson AR, Hicks KJ, Dewit $\mathrm{OE}, \mathrm{Aziz} \mathrm{Q}$. Human visceral pain hypersensitivity is not attenuated by neurokinin-1 (NK-1) receptor antagonism. Gastroenterology 2006; 130 (Suppl 2): A26-A27. (abstract).

205 Kirkup AJ, Brunsden AM, Grundy D. Receptors and transmission in the brain-gut axis: potential for novel therapies. I. Receptors on visceral afferents. Am J Physiol Gastrointest Liver Physiol 2001; 280: G787-94.

206 Hornby PJ, Prouty SM. Involvement of cannabinoid receptors in gut motility and visceral perception. $\mathrm{Br} J$ Pharmacol 2004; 141: 1335-45. 